\title{
A STUDY OF BREAST-FEEDING PRACTICES AMONG MOTHERS OF INFANTS WHO ARE ATTENDING OUTPATIENT SERVICES AT A TERTIARY CARE HOSPITAL, NIZAMABAD
}

\author{
Gopal Singh Khetavath ${ }^{1}$, Vanagondi K. Kavitha²
}

${ }^{1}$ Assistant Professor, Department of Paediatrics, GMC, Nizamabad.

${ }^{2}$ Associate Professor, Department of Paediatrics, GMC, Nizamabad.

ABSTRACT

\section{BACKGROUND}

Breast milk is the ideal food for an infant under any circumstance. No other food is required by the infant until six months after birth. Exclusive breast-feeding protects the infant from early malnutrition and infections. Prelacteal feeds are not necessary as breast milk is easily digestible. Benefits of breast-feeding get diluted as its exclusivity decreases. Establishment of lactation starts with early initiation of breast-feeding.

Objectives- To assess the breast-feeding and infant feeding practices among mothers of infants aged 0-12 months.

\section{MATERIALS AND METHODS}

This hospital-based cross-sectional study was carried out from February to March 2017 among mothers of infants in Paediatric OP, Government medical college, Nizamabad. 100 study subjects were selected by simple random sampling. The data recorded in the predesigned questionnaire was used to study the breast-feeding and infant feeding practices among them. Statistical analysis was done using MS office, MS Excel, Epi Info.

\section{RESULTS}

Out of 100 mothers, 56 belonged to 21-25 years of age. 58 were Hindus. 56 had male infants and 44 had female infants. 58 had initiated breast feeds within the first one hour of birth.

\section{CONCLUSION}

The present study shows that the breast-feeding practices in the study subjects, though close to the national averages, need constant monitoring to reach the present goals of infant and young child nutrition, set under the National Nutrition Policy. The various opportunities for maternal and child health contacts available at the community level and health facility level must be utilised to reinforce the key messages centring around infant and young child feeding, growth monitoring and promotion. Optimal breast-feeding and complementary feeding practices together allow children to reach their full growth potential.

\section{KEYWORDS}

Infants, Complementary Feeding, Exclusive Breast-feeding,

HOW TO CITE THIS ARTICLE: Khetavath GS, Kavitha VK. A study of breast-feeding practices among mothers of infants who are attending outpatient services at a tertiary care hospital, Nizamabad. J. Evolution Med. Dent. Sci. 2017;6(51):3903-3905, DOI: 10.14260/Jemds/2017/844

\section{BACKGROUND}

Breast-feeding, also known as nursing, is the feeding of babies and young children with milk from a woman's breast. ${ }^{1}$ Health professionals recommend that breast-feeding begin within the first hour of a baby's life and continue as often and as much as the baby wants. ${ }^{2,3}$ During the first few weeks of life babies may nurse roughly every two to three hours. The duration of a feeding is usually ten to fifteen minutes on each breast. ${ }^{4}$ Breast-feeding has a number of benefits to both mother and baby, which infant formula lacks. 3,5

Deaths of an estimated 820,000 children under the age of five could be prevented globally every year with increased breast-feeding. ${ }^{6}$ Breast-feeding decreases the risk of

Financial or Other, Competing Interest: None.

Submission 03-05-2017, Peer Review 14-06-2017,

Acceptance 19-06-2017, Published 24-06-2017.

Corresponding Author:

Dr. Gopal Singh Khetavath,

Assistant Professor,

Department of Paediatrics,

GMC, Nizamabad.

E-mail: drgopalsinghketavath@yahoo.com

DOI: $10.14260 /$ jemds $/ 2017 / 844$

respiratory tract infections and diarrhoea, both in developing and developed countries. ${ }^{2,3}$ Other benefits include lower risks of asthma, food allergies, coeliac disease, type 1 diabetes, and leukaemia. ${ }^{3}$ Breast-feeding may also improve cognitive development and decrease the risk of obesity in adulthood. ${ }^{2}$ Mothers may feel pressure to breast-feed; however, in the developed world children generally grow up normally bottle fed. ${ }^{7}$

Health organisations, including the World Health Organization (WHO), recommend breast-feeding exclusively for six months. ${ }^{8}$ This means that no other foods or drinks other than possibly vitamin $\mathrm{D}$ are typically given. After the introduction of foods at six months of age, recommendations include continued breast-feeding until at least one to two years of age.2,3 Globally about $38 \%$ of infants are breastfed only during their first six months of life. ${ }^{2}$ In the United States, about $75 \%$ of women begin breast-feeding and about $13 \%$ only breast-feed until the age of six months. ${ }^{3}$

Breast-feeding though traditional in our country, is associated with myths and superstitions like colostrum being bad for the baby, etc. ${ }^{9}$ Early introduction of complementary feeds leads to infections and contributes to undernutrition and infant mortality. Studies have shown that up to $70 \%$ of newborn deaths can be averted by ensuring clean delivery, 
care of low birth weight babies by providing warmth, early initiation of exclusive breast-feeding, hygienic eye and cord care, and early recognition and treatment of illness. ${ }^{10}$ The urban population is rapidly expanding because of the largescale migration of people to the cities and it is projected that more than half of the Indian population will live in urban areas by 2020 and that nearly one third of this urban population would have been slum dwellers previously. ${ }^{11}$ Rapid urbanisation has led to falling breast-feeding rates, which has a direct effect on infant nutrition and health status. The need to assess knowledge and attitude on initiation of breast-feeding and establishing lactation is crucial to the success of any effort taken up to promote breast-feeding among mothers in the community. It was in this context that the present study was undertaken to assess the breastfeeding practices and infant feeding practices among mothers of infants.

\section{MATERIALS AND METHODS}

A hospital-based observational study among mothers of infants aged 0-12 months, was undertaken during February to March 2017, in Government General Hospital, Nizamabad, Telangana. A predesigned, pretested proforma was developed and pilot tested. The mothers of children were interviewed separately.

\section{Study Design}

The present study was a hospital-based, observational, crosssectional study.

\section{Study Setting}

Study was conducted at Government General Hospital, Nizamabad.

\section{Selection of Study Subjects}

Mothers of infants aged 0-12 months.

\section{Sample Size}

100 Mothers of infants aged 0-12 months.

\section{Inclusion Criteria}

Mothers of infants aged 0-12 months who are attending outpatient services at Paediatric Ward, Government Medical College.

\section{Exclusion Criteria}

Those not giving consent for the study.

\section{Statistical Analysis}

MS Office, MS Excel, Epi info 2005 statistical software were used to derive statistical inferences whenever necessary. Simple proportions, percentages and Chi square test were used to summaries the data.

\section{RESULTS}

\begin{tabular}{|c|c|}
\hline Age & Number of Mothers \\
\hline $15-20$ & 23 \\
\hline $21-25$ & 56 \\
\hline $26-30$ & 18 \\
\hline$>31$ & 3 \\
\hline Table 1. Age wise Distribution of Study Population \\
\hline
\end{tabular}

100 mothers of infants aged 0-12 months were included in this study. Majority belonged to 21-25 years age group.

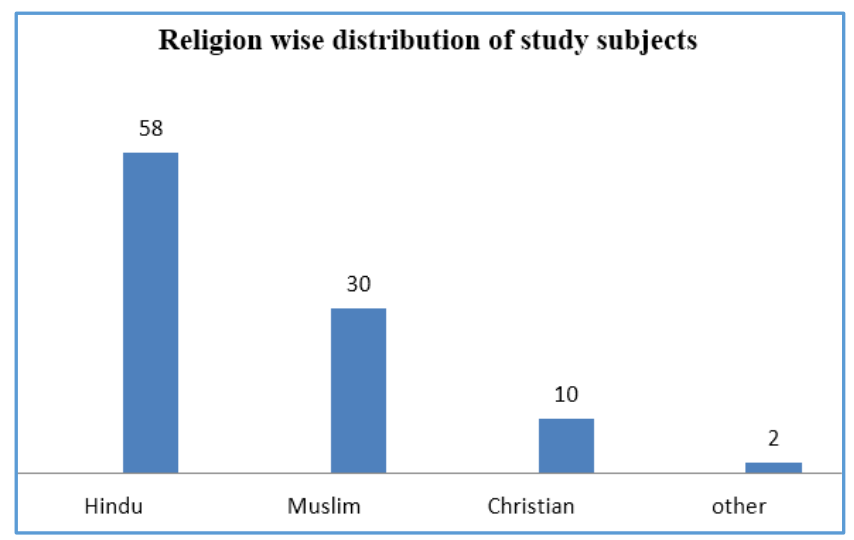

Table 2. Religion wise Distribution of Study Subjects

Most of the study population was Hindus (58) followed by Muslims (30), Christians (10) and others (2).

\begin{tabular}{|c|c|c|c|}
\hline Age in Months & Males & Females & Total \\
\hline 0-6 months & 23 & 21 & 44 \\
\hline 6-12 months & 33 & 23 & 56 \\
\hline Total & $\mathbf{5 6}$ & $\mathbf{4 4}$ & $\mathbf{1 0 0}$ \\
\hline \multicolumn{3}{|c|}{$\begin{array}{l}\text { Table 3. Age and Sex Wise Distribution } \\
\text { of the Infants of the Study Subjects }\end{array}$} \\
\hline
\end{tabular}

56 of the mothers had male and 44 had female infants as shown in Table 3.

\begin{tabular}{|c|c|}
\hline Duration in Hours & Number of Children \\
\hline$<1$ hour & 58 \\
\hline 1 to 4 hours & 25 \\
\hline 12 hours or more & 17 \\
\hline Total & $\mathbf{1 0 0}$ \\
\hline Table 4. Initiation of Breast-feeding among the Mothers \\
\hline
\end{tabular}

Table 4 shows that 58 of the mothers initiated breastfeeding within one hour of delivery and 25 within one to four hours.

\begin{tabular}{|c|c|}
\hline $\begin{array}{c}\text { Source of } \\
\text { Knowledge }\end{array}$ & $\begin{array}{c}\text { Number of Mothers, } \\
\quad \mathrm{N}=136(100 \%)\end{array}$ \\
\hline Family members & 30 \\
\hline Doctor and Health worker & 56 \\
\hline Others & 14 \\
\hline Total & 100 \\
\hline \multicolumn{2}{|c|}{ Table 5. Source of Knowledge regarding Breast-feedin } \\
\hline
\end{tabular}

The source of knowledge regarding breast-feeding among these mothers was from health personnel i.e. Doctor and health workers in 56 as seen in Table 5 .

Family i.e. near kith and kin was the second most common source in 30 .

\begin{tabular}{|c|c|}
\hline Number of Times in 24 Hours & Number of Infants \\
\hline$<6$ times & 17 \\
\hline 6-8 times & 64 \\
\hline $8-12$ times & 16 \\
\hline$>12$ times, demand feeds & 3 \\
\hline Total & 100 \\
\hline \multicolumn{2}{|c|}{$\begin{array}{l}\text { Table 6. Frequency of Breast-feeds } \\
\text { among the Infants of these Mothers }\end{array}$} \\
\hline
\end{tabular}


Table 6 shows that 64 mothers breastfed their infants for about 6-8 times in a day. A very small proportion of the mothers (3) were breast-feeding on demand.

\section{DISCUSSION}

In the present study, 100 mothers of infants aged 0-12 months were included. Majority belonged to 21-25 year age group. Most of the study population was Hindus (58) followed by Muslims (30), Christians (10) and others (2). 56 of the mothers had male and 44 had female infants as shown in Table 3.

In the present study, 56 mothers initiated breast-feeding within one hour of delivery, whereas in NFHS-3 it was reported that in Andhra Pradesh, 22.4\% of children under 3 years were breastfed within one hour of birth, $62.7 \%$ were exclusively breastfed for 6 months and complementary feeds were started at the age of 6 months and they were still being breastfed in $63.7 \%$ whereas at the national level, it was $23.4 \%, 46.3 \%$ and $55.8 \%$ respectively. ${ }^{12}$ The present finding of exclusive breast-feeding is more when compared to the earlier studies of Tiwari et $\mathrm{al}^{13}$ and Roy $\mathrm{S}$ et al.14 Complementary feeds were introduced at 6 months by 53 mothers in this study which was less than that in other studies, Roy S et al.14 In a similar study conducted in an urban slum of Nagpur, $32.56 \%$ had started breast-feeding within 1 hour after delivery. Colostrum was given by $21.38 \%$ mothers. Exclusive breast-feeding for 6 months was given by $36.84 \%$ mothers. Complementary feeds were introduced at 6 months by $158(41.11 \%)$ mothers. ${ }^{15}$ Roy et al reported that $34.22 \%$ of the mothers had been informed about breast-feeding by the health personnel while in the present study it was $56.61 \%$ and Tiwari et al in their study found that only $3.85 \%$ of the mothers had been informed.11,12 Appropriate feeding during illness is important to prevent nutritional deficiencies and in the present study, $88.23 \%$ continued to breast-feed their infants during episodes of diarrhoea. Inappropriate infant feeding practices is one of the important causes of malnutrition as has been reported by a study carried out by Ghosh et al. ${ }^{16}$ The source of knowledge regarding breastfeeding among these mothers was from health personnel i.e. doctor and health workers in 56 as seen in Table 5. Family i.e. near kith and kin was the second most common source in 30 . Table 6 shows that 64 mothers breastfed their infants for about 6-8 times in a day. A very small proportion of the mothers (3) were breast-feeding on demand.

\section{CONCLUSION}

The present study shows that the breast-feeding practices in the study subjects, though close to the national averages, need constant monitoring to reach the present goals of infant and young child nutrition, set under the National Nutrition Policy.

The various opportunities for maternal and child health contacts available at the community level and health facility level must be utilised to reinforce the key messages centring around infant and young child feeding, growth monitoring and promotion.
Optimal breast-feeding and complementary feeding practices together allow children to reach their full growth potential.

\section{REFERENCES}

[1] Breast-feeding and breast milk: condition information. 2013-12-19. 2015.

[2] Infant and young child feeding Fact sheet $\mathrm{N}^{\circ} 342$. WHO, 2015.

[3] Eidelman AI, Schanler RJ, Johnston M, et al. Breastfeeding and the use of human milk. Pediatrics 2012;129(3):e827-41.

[4] How do I breastfeed? Skip sharing on social media links. 2014-04-14. 2015.

[5] Ip S, Chung M, Raman G, et al. A summary of the Agency for Healthcare Research and Quality's evidence report on breast-feeding in developed countries. Breast-feeding Medicine 2009;4(Suppl 1):S17-30.

[6] Victora CG, Bahl R, Barros AJ, et al. Breast-feeding in the 21st century: epidemiology, mechanisms, and lifelong effect. The Lancet 2016;387(10017):475-90.

[7] Lawrence RA, Lawrence RM. Breast-feeding: a guide for the medical professional. Elsevier Health Sciences 2010.

[8] Kramer MS, Kakuma R. Optimal duration of exclusive breast-feeding. Cochrane Database of Systematic Reviews 2012;8:CD003517.

[9] Pandit N, Yeshwanth M, Albuquerque SI. Factors influencing initiation of breast-feeding in an urban set up. Indian Pediatrics 1994;31(12):1558-60.

[10] Tinker A, Parker R, Lord D, et al. Advancing newborn health: the saving newborn lives initiative. Global Public Health 2010;5(1):28-47.

[11] International Institute for Population Sciences, ORC Macro. MEASURE/DHS+ (Programme). India National Family Health Survey (NFHS-2), 1998-99. International Institute for Population Sciences, Mumbai, India 2000.

[12] International Institute for Population Sciences. India National Family Health Survey (NFHS-3), 2005-06. International Institute for Population Sciences 2007.

[13] Tiwari R, Mahajan PC, Lahariya C. The determinants of exclusive breast-feeding in urban slums: a community based study. Journal of Tropical Pediatrics 2009;55(1):49-54.

[14] Roy S, Dasgupta A, Pal B. Feeding practices of children in an urban slum of Kolkata. Indian Journal of Community Medicine 2009;34(4):362-3.

[15] Bagul AS, Supare MS. The infant feeding practices in an urban slum of Nagpur, India. Journal of Clinical and Diagnostic Research 2012;6(9):1525-7.

[16] Ghosh S, Shah D. Nutritional problems in urban slum children. Indian Pediatrics 2004;41(7):682-96. 